\title{
DO-G persönlich
}

\section{Frau Vesta Stresemann zum 100. Geburtstag!}

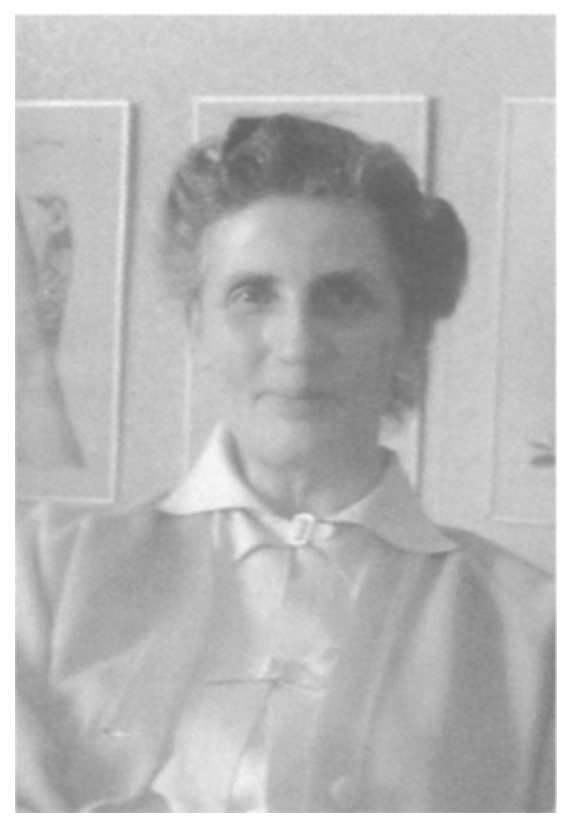

Frau Vesta Stresemann,

Berlin im September 1959 (Foto: E. Nowak)
Frau Vesta Stresemann, Mitglied der Deutschen Ornithologischen Gesellschaft seit 1939, wird am 16. Oktober d. J. in Freiburg i. Br. ihren 100. Geburtstag feiern!

Während des Krieges, im September 1941. heiratete Frau Vesta, geb. Grote (verwitwete Hauchecorne), Professor Erwin Stresemann und nahm helfend an seiner wissenschaftlichen Arbeit teil.

Auch sie musste viele durch den Krieg verursachte Schwierigkeiten ertragen: die Flucht vor der anrückenden Front nach Westen; die Heimkehr nach Berlin, ,schwarz" über die Zonengrenze; danach die bescheidenen Wohnverhältnisse, da ihr Haus in Lichterfelde-West von US-Amerikanern beschlagnahmt wurde, und nicht zuletzt die Bewältigung aller Krisen, welche die geteilte Stadt während des Kalten Krieges einem Westberliner, der im Ostteil der Stadt tätig war, bescherte (Berlin-Blockade, Volksaufstand, Mauerbau u. a. m.).

In allen diesen Jahren stand Frau Vesta menschlich und fachlich ihrem Ehemann zur Seite und schuf ihm Freiräume für seine intensive wissenschaftliche Arbeit. In späteren Nachkriegsjahren begleitete sie ihren Mann auf Reisen zu vielen Tagungen und Forschungsaufenthalten im Ausland. Nach seiner Pensionierung, als er sich vornehmlich mit der Mauser der Vögel befasste, untersuchte sie für ihn viele tausend Bälge in diversen Sammlungen; aus ihrer Hand stammen etwa 5000 Mauserprotokolle einzelner Vögel. Die intensive Zusammenarbeit führte zu mehreren gemeinsamen Publikationen, vor allem jedoch dem 1966 von Erwin und Vesta Stresemann veröffentlichten Buch über „Die Mauser der Vögel“. Ohne ihre Hilfe hätte das Werk Stresemanns in den Kriegs- und insbesondere in den Nachkriegsjahren nicht den Umfang erreichen können, den er uns hinterlassen hat. Auch nach dem Tod ihres Mannes im Jahre 1972 nahm Frau Vesta an Ornithologen-Tagungen teil, u. a. an der 100. Jahresversammlung der DO-G in Bonn im Jahre 1988 und am Jubiläumskolloquium anlässlich des 100. Geburtstages Stresemanns in (damals noch Ost-) Berlin im Jahre 1989. Seit 1981 lebt Frau Vesta in Freiburg, betreut von ihrer Tochter Amélie Koehler.

Die Deutsche Ornithologen-Gesellschaft gratuliert Frau Vesta Stresemann ganz herzlich! E. Nowak, F. Bairlein 